\title{
Effect of School-Based Stepping Stones Triple P on Child and Parent Outcomes
}

\author{
Anagha Aery ${ }^{1 *}$, Julie Hodges ${ }^{2}$, Jamin Day $^{3}$ \\ 1,2,3. The University of Queensland, Brisbane, Australia \\ *E-mail: anagha.aery@uq.net.au
}

\begin{abstract}
This paper investigated the effectiveness of delivering Stepping Stones Triple P (SSTP), a parenting intervention program, in special education settings and by education professionals to positively influence the potential of families of children with a disability. Questionnaire responses from 216 parents of children with a disability who received SSTP in special education settings and by education staff were extracted from a pre-existing dataset. The questionnaires were administered before and after the program and again 12 months later. Questionnaires included measures of child problem behaviour, parenting practices, parental adjustment, parental self-efficacy, and program satisfaction. Results from a series of MANOVA and ANOVAs revealed significant improvements in parent-reported child behaviour, parenting practices, parental adjustment and parental efficacy. Results were maintained at 12-month follow-up. Qualitative comments revealed that $35 \%$ of parents continued to seek support from education professionals due to the positive experience. Overall, these findings suggest that school-based SSTP is effective in enhancing the behaviour of children with disabilities by augmenting the skillset and confidence of their parents. An avenue for future research is to specifically explore the effect of school-based SSTP on the partnership between home and school.
\end{abstract}

\section{Keywords: home-school partnership; school-based parenting intervention}

\section{Introduction}

Parents are the first educators of children and are responsible for teaching them basic life skills such as language, communication, social and adaptive skills. Parents' responsibility also extends to providing their child a safe and nurturing environment where they can learn and grow (Suter, 2006). However, home is not the sole environment that influences the learning and development of a child.

The ecological systems theory conceptualizes a child's development as being influenced directly by their immediate surroundings such as their home, school, and neighbourhood, and indirectly by more distal influences such as the nature of parents' work or the cultural values of the family (Bronfenbrenner, 1977). The primary proposition of this model is that the environments of a child are interconnected (Jack, 2000), and maximises benefit for the child when they interact positively (Glueck \& Reschly, 2014).

The notion of home-school partnership (HSP) encapsulates the interaction between home and school, which are the two most important learning environments for children. It is defined as a shared responsibility between families and schools in children's education, whereby mutual collaboration, respect and support help promote children's academic, social, emotional, and behavioural outcomes (Patrikakou, Weissberg, Redding, \& Walberg, 2005). The higher the congruence in goals and methods between the home and school, the more prominent the gains in learning are for the child as the child receives consistent messages across his or her major learning environments (Epstein, 2010; Sheridan \& Moorman, 2015). Based on previous research on the impact of HSP, a positive and effective HSP was found to enhance children's academic success (Wilder, 2014), self-confidence (Sterian \& Mocanu, 2013), positive behaviour (Sheldon \& Epstein, 2002; Sterian \& Mocanu, 2013), and social and emotional well-being (Avvisati, Gurgand, Guyon, \& Maurin, 2014).

The non-academic benefits of a positive HSP are especially advantageous for children with developmental disabilities, as these children display substantially higher rates of social, emotional, and behavioural problems than typically developing 
children (Alimovic, 2013). Furthermore, parents of children with a disability will experience a natural sense of grief and guilt and feel uncertain about how to manage the unique demands of the child (Roux, Sofronoff, \& Sanders, 2013). This increases their likelihood of engaging in poor parenting practices (Moes \& Frea, 2000), which can maintain or further exacerbate behavioural problems in children (Eddy, Leve, \& Fagot, 2001), both at home and at school. Given that disruptive behaviour in school can increase teachers' stress and hinder learning in the classroom (Clunies-Ross, Little, \& Kienhuis, 2008), it would be in the best interest of schools to support parents in managing their child's disability.

Parenting programs are an established method of empowering parents and fostering positive wellbeing in children. Stepping Stones Triple P (SSTP) is one such parenting intervention and is especially designed to meet the needs of parents and caregivers of children with a developmental disability (Sanders, Mazzucchelli, \& Studman, 2004). Studies investigating the efficacy of SSTP have consistently shown to improve child behaviour, parenting practices, parental satisfaction and parental adjustment to the child's disability, and reduce parental stress (Hodgetts, Savage, \& McConnell, 2013; Roberts, Mazzucchelli, Studman, \& Sanders, 2006; Roux et al., 2013; Sofronoff, Jahnel, \& Sanders, 2011; Tellegen \& Sanders, 2013; Whittingham, Sofronoff, Sheffield, \& Sanders, 2009). These effects were maintained at 3- to 6month follow-up.

The effect of SSTP on parental self-efficacy is less clear with some studies indicating a positive effect (Hodgetts et al., 2013) whilst others demonstrating a delayed effect where self-efficacy only increased at follow-up (Sofronoff et al., 2011; Whittingham et al., 2009). This inconsistency in results could be because different levels of SSTP intervention are explored in these studies. SSTP incorporates five levels of intervention with increasing levels of intensity. Level 2 interventions (e.g. large-group seminars) give parents ideas and strategies, but do not involve active rehearsal of parenting skills. This is likely to mean that parents' ability to independently implement strategies may be reduced (Sanders et al., 2004). Consistent with this, a metaanalysis by Tellegen and Sanders (2013) found an increase in parental self-efficacy at post-intervention when results were collapsed across intervention levels, but no effect for Level 2 seminars alone.

Despite documented evidence of the positive impact of SSTP on parent and child outcomes, parenting programs alone are deficient in providing parents with comprehensive support to manage children's behaviour across settings. Children with disabilities thrive on consistency across their learning environments (Sheridan \& Moorman, 2015). For instance, the effort of a parent to reduce disruptive behaviour will be futile if the classroom teacher inadvertently reinforces the same negative behaviour and vice versa, because the child receives inconsistent messages across their home and school. Consequently, there remains a need to identify a method of not only empowering parents but also fostering consistency in practice for the child between their home and school. Although attempts by governments and schools to build HSP are appealing in theory, there remain barriers to effective HSP in practice, such as power struggles, low selfefficacy, and lack of understanding between parents and teachers (Bano, Anjum, Rahman, Sadia, \& Sarwar, 2013).

In this paper, we propose school-based SSTP as a way to facilitate HSP. We define school-based SSTP as SSTP that is delivered in a special education setting (e.g. special school, early learning, and development centre) and by an education staff (e.g. teacher, guidance counsellor). By involving both the parent and the teacher in the program, we suggest that there would be a greater opportunity for communication and collaboration between home and school. Additionally, education professionals, by virtue of their role as facilitator, would be trained in the same positive practices as parents, thereby enhancing consistency for the child.

Prior to exploring the effect of school-based SSTP on HSP, it is important to confirm its primary effects on child and parent outcomes. Despite extensive research on the efficacy of SSTP, there remains the question of whether these established benefits have external validity, as efficacy trials are highly controlled and adopt strict inclusion and exclusion criteria. To our knowledge, no studies have explored the effectiveness of SSTP when delivered by education professionals in school settings. Such research would have important implications for the generalisability of SSTP in real-world settings where there is less opportunity to control for confounds, including facilitators' characteristics and level of struggles experienced by parents and children. Furthermore, implementing SSTP in schools would significantly increase its reach because it would provide a destigmatising context for parenting interventions when schools encourage all parents to attend (Sanders, Healy, Grice, \& Del Vecchio, 2017). Finally, understanding the effectiveness of school-based SSTP on parent and child outcomes 
would qualify the exploration of its effect on HSP, as there is currently a need to identify an effective method of fostering HSP (Bano et al., 2013).

This study aims to explore the effectiveness of school-based SSTP in enhancing parent and child outcomes. By extracting data from a larger SSTP program rollout, we assessed change in child behaviour and parental outcomes before and after participation in school-based SSTP and again 12 months later. Participants' satisfaction with the program was also assessed after the intervention. We hypothesised that participating in a school-based SSTP would result in decreased problem behaviour in children, and improved parenting practices, parental adjustment, and parenting self-efficacy. It was expected that these effects would be maintained at 12-month follow-up. We also explored whether these effects are moderated by the level of intervention (seminar or group). Stronger effects of the intervention were anticipated for participants in the group intervention as opposed to the seminar.

\section{Methods}

Sample. Participants were 216 parents and primary caregivers (both of whom will hereafter be referred to as parents) of a child with a disability aged 2-12 years $(M=5.58, S D=2.48) .81 \%$ of the children were boys. $96 \%$ of children were diagnosed with Autism Spectrum Disorder (autism, Asperger's syndrome, and Pervasive Developmental DisorderNot Otherwise Specified). The majority of households included original families (71.29\%; both biological or adoptive parents present) and $17.59 \%$ were single-parent households. Parents' age at the birth of the child ranged between 25 and $83(M=$ $41.75, S D=8.89$ ), and $87.69 \%$ of parents spoke English at home. This study did not involve direct recruitment as existing data of parents who participated in SSTP in an education setting in Queensland was extracted from a larger Stepping Stones Triple P Project. This larger project was a tristate (Queensland, New South Wales, and Victoria) program rollout that provided parents of children with a disability-free access to SSTP intervention and resources for the duration of the program.

Procedure. The original Stepping Stones Triple P Project dataset contained de-identified responses to several measures from over a 1000 parents that received SSTP in a variety of settings, such as community centres, disability support centres, schools, early learning and development centres and university clinics, and by a variety of practitioners including psychologists, disability support workers, occupational therapists, teachers, and guidance counsellors. For this study, only questionnaire responses from participants that received SSTP in an educational setting (e.g. schools, early learning centres) and by an education professional (e.g. teacher, guidance counsellor) was extracted to form a school-based SSTP dataset (see Figure 1). Parents were classified into the level of intervention in which they chose to participate (i.e. seminar or group).

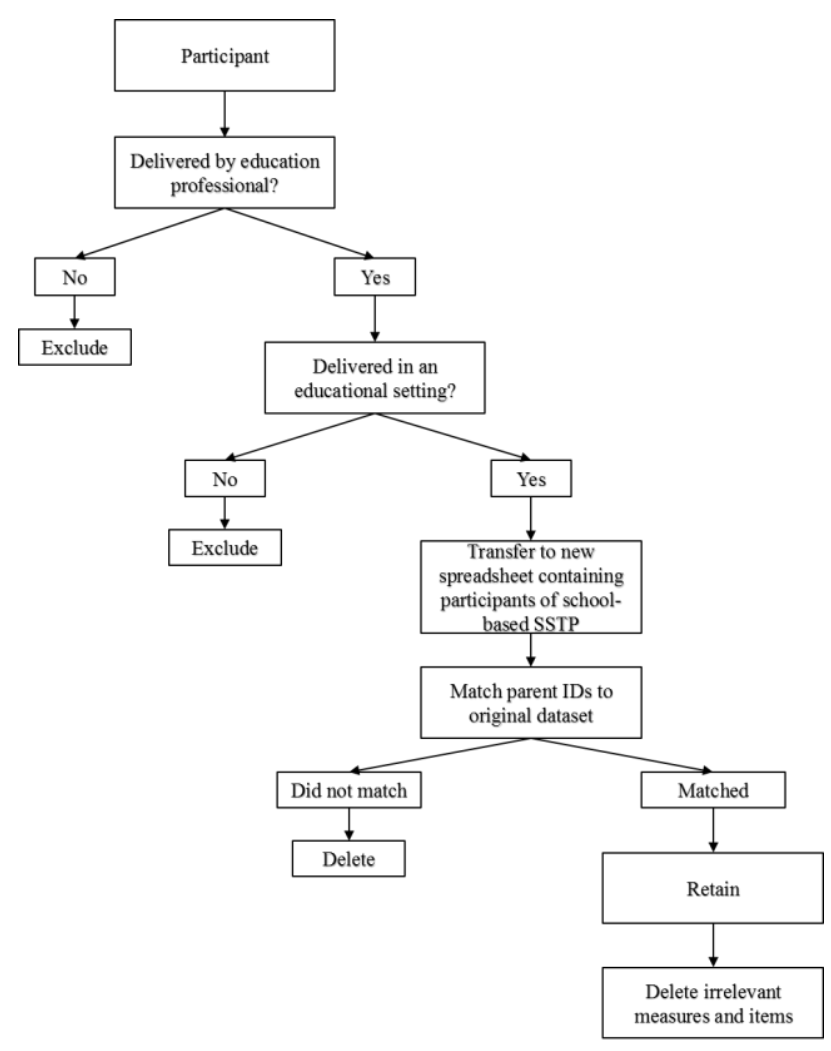

Figure 1. The procedure for data extraction.

Research Design. A longitudinal research design was applied to observe quantitative changes in child and parent outcomes before and after the parenting intervention, and at 12-month follow-up. The effect of intervention level (seminar versus group) on parent and child outcomes was also explored.

Instrument and Measurement. Coercive parenting, parental consistency, positive encouragement, and parent-child relationship were assessed using different items in the Parenting Scale of the Parenting and Family Adjustment Scales (PAFAS; Mazzucchelli et al., 2017). Parental adjustment was assessed using five items in the Family Adjustment Scale of the PAFAS. Responses were scored on a 4-point Likert scale $(0=$ not at all, $3=$ very $\mathrm{much} /$ most of the time). Scores for each set of items were summed, where higher scores 
indicated higher levels of dysfunctional parenting and poorer parental adjustment. The reliabilities were adequate for the Parenting Scale $(\alpha=.69)$ and the parental adjustment subscale $(\alpha=.79)$ in this sample. The convergent validity for the PAFAS subscales ranges from .09 to .36 (Mazzucchelli et al., 2017).

The 13-item Intensity Scale in the Child Adjustment and Parent Efficacy Scale - Developmental Disabilities (CAPES-DD; Emser, Mazzucchelli, Christiansen, \& Sanders, 2016) was used to measure child problem behaviour. Parents rated statements of their child based on how true they were $(0=$ not true at all, 3 = true of my child very much, or most of the time). Ratings were summed where higher scores indicated higher levels of problem behaviour in children. The Intensity Scale demonstrated good reliability in this sample $(\alpha=.86)$, and has moderate to high convergent validity, ranging from .39 to .85 (Emser et al., 2016)

The 13-item Self-Efficacy scale in the CAPES-DD (Emser et al., 2016) was used to measure parents' self-efficacy on managing their child's disabilityrelated problem. Responses were provided on a 10point Likert scale $(1=$ certain I can't manage it, 10 = certain I can manage it). Scores were summed, with higher scores indicative of greater parenting efficacy. The reliability of this scale was good $(\alpha=$ $.91)$ and the predictive validity ranges from .14 to .42 (Emser et al., 2016).

Participants' satisfaction with the program was measured using the Client Satisfaction Questionnaire (CSQ; Turner, Sanders, \& MarkieDadds, 2002). Thirteen items were scored on 7point Likert scales and three items allowed for open-ended responses. Scores were averaged, with higher scores indicating greater satisfaction with the program. The CSQ demonstrated good reliability in this study $(\alpha=.96)$.

Table 1 summarises a sample item for each outcome variable.

\section{Results}

A series of 3 (time: pre-intervention, postintervention, 12-month follow-up) x 2 (intervention level: seminar, group) mixed multivariate analysis of variance (MANOVAs) and univariate analysis of variance (ANOVAs) were performed to examine the effect on several child and parent outcomes, with time as the within-subjects factor. Bonferroni adjustment was applied to the alpha level when evaluating the follow-up contrasts (pre- to postintervention, pre-intervention to follow-up), producing an adjusted alpha level of .025. In cases where the Mauchly's test indicated that the assumption of sphericity had been violated, degrees of freedom were corrected using GreenhouseGeisser estimates of sphericity.

Table 1.

Sample items for all outcome variables and item numbers for PAFAS subscales. Note. $\mathrm{R}$ indicates reverse-scored item.

\begin{tabular}{|c|c|c|c|}
\hline Measure & $\begin{array}{l}\text { Outcome } \\
\text { Variable }\end{array}$ & $\begin{array}{c}\text { Item } \\
\text { Number }\end{array}$ & $\begin{array}{l}\text { Sample } \\
\text { Item }\end{array}$ \\
\hline \multirow[t]{5}{*}{ PAFAS } & $\begin{array}{l}\text { Parental } \\
\text { consistency }\end{array}$ & $\begin{array}{l}1,4,11- \\
\mathrm{R}, 12\end{array}$ & $\begin{array}{l}\text { If my child } \\
\text { doesn't do } \\
\text { what they're } \\
\text { told I give in }\end{array}$ \\
\hline & $\begin{array}{l}\text { Coercive } \\
\text { parenting }\end{array}$ & $\begin{array}{l}5,7,9, \\
10,13\end{array}$ & $\begin{array}{l}\text { I spank } \\
\text { (smack ) my } \\
\text { child when } \\
\text { they } \\
\text { misbehave }\end{array}$ \\
\hline & $\begin{array}{l}\text { Positive } \\
\text { encouragement }\end{array}$ & $\begin{array}{l}\text { 2-R, 6-R, } \\
\text { 8-R }\end{array}$ & $\begin{array}{l}\text { I praise my } \\
\text { child if they } \\
\text { behave well }\end{array}$ \\
\hline & $\begin{array}{l}\text { Parent-child } \\
\text { relationship }\end{array}$ & $\begin{array}{l}\text { 14-R, 16- } \\
\text { R, 17-R, } \\
18-\mathrm{R}\end{array}$ & $\begin{array}{l}\text { I enjoy } \\
\text { spending } \\
\text { time with } \\
\text { my child }\end{array}$ \\
\hline & $\begin{array}{l}\text { Parental } \\
\text { adjustment }\end{array}$ & $\begin{array}{l}\text { 19, 20-R, } \\
21,22-\mathrm{R}, \\
23-\mathrm{R}\end{array}$ & $\begin{array}{l}\text { I feel } \\
\text { stressed or } \\
\text { worried }\end{array}$ \\
\hline \multirow[t]{2}{*}{$\begin{array}{l}\text { CAPES- } \\
\text { DD }\end{array}$} & $\begin{array}{l}\text { Child problem } \\
\text { behaviour }\end{array}$ & & $\begin{array}{l}\text { Loses their } \\
\text { temper }\end{array}$ \\
\hline & $\begin{array}{l}\text { Parental self- } \\
\text { efficacy }\end{array}$ & & $\begin{array}{l}\text { Demands } \\
\text { attention }\end{array}$ \\
\hline CSQ & $\begin{array}{l}\text { Program } \\
\text { satisfaction }\end{array}$ & & $\begin{array}{l}\text { To what } \\
\text { extent has } \\
\text { the program } \\
\text { met your } \\
\text { needs? }\end{array}$ \\
\hline
\end{tabular}

Table 2 displays the descriptive statistics for the outcome variables at each time-point. The main effect of intervention level on the outcome variables and the interaction between time and intervention level were non-significant in all analyses. The reported results are the main effects of time. 
Table 2.

Means and standard deviations (in parentheses) for all outcome variables at each time-point.

\begin{tabular}{llcc}
\hline \multicolumn{1}{c}{ Outcome } & \multicolumn{3}{c}{ Intervention Time } \\
\cline { 2 - 4 } \multicolumn{1}{c}{ Variable } & \multicolumn{1}{c}{ Pre } & Post & Follow-up \\
\hline Parental & 4.16 & 3.48 & 3.29 \\
consistency & $(1.84)$ & $(1.77)$ & $(1.48)$ \\
\hline Coercive & 4.19 & 3.43 & 3.15 \\
parenting & $(2.42)$ & $(1.90)$ & $(1.45)$ \\
\hline Positive & 1.97 & 1.69 & 1.72 \\
encouragement & $(1.66)$ & $(1.30)$ & $(1.12)$ \\
\hline Parent-child & 1.75 & 1.42 & 1.48 \\
relationship & $(1.80)$ & $(1.42)$ & $(1.31)$ \\
\hline Parental & 6.52 & 5.72 & 5.62 \\
adjustment & $(3.00)$ & $(2.47)$ & $(2.33)$ \\
\hline Child problem & 15.07 & 13.74 & 13.16 \\
behaviour & $(7.09)$ & $(6.17)$ & $(4.85)$ \\
\hline Parental self- & 86.59 & 97.55 & 97.72 \\
efficacy & $(22.42)$ & $(19.03)$ & $(16.42)$ \\
\hline
\end{tabular}

Results of the MANOVA assessing parenting practices revealed a significant effect of time $F(8$, $852)=10.56, p<.001$; Pillai's $\mathrm{V}=.180$. When the dependent variables were examined in separate univariate analyses, there were significant main effects of time on parental consistency, $F(1.85$, $395.85)=28.84, p<.001$, coercive parenting, $F(1.87,400.94)=28.72, p<.001$, positive encouragement $F(1.88,404.27)=4.40, p=.014$, and parent-child relationship, $F(1.91,407.71)=$ 5.22, $p=.007$. Follow-up tests indicated a significant improvement from pre- to postintervention in all dependent variables of parenting practices, $F(1,214)>6.30, p<.013$. Using a stringent alpha level, parental consistency and coercive parenting reduced significantly from preintervention to follow-up $F(1,214)>44.90, p<$ .001 , and positive encouragement and parent-child relationship just approached significance $F(1,214)>$ $5.38, p<.021$. Therefore, participation in schoolbased SSTP produced improvements in all measures of parenting practices, although the improvements were more profound for parental consistency and coercive parenting.

Results from the ANOVA examining parental adjustment demonstrated that the main effect of time on parental adjustment was significant, $F(1.84$, $393.76)=16.31, p<.001$. Follow up contrasts revealed that parental adjustment improved significantly from pre- to post intervention, $F(1$, $214)=22.36, p<.001$, and at follow-up, $F(1,214)=$ $22.25, p<.001$. This indicates that receiving schoolbased SSTP helped parents to cope better emotionally. Figure 2 displays the findings of the aforementioned parent outcomes.

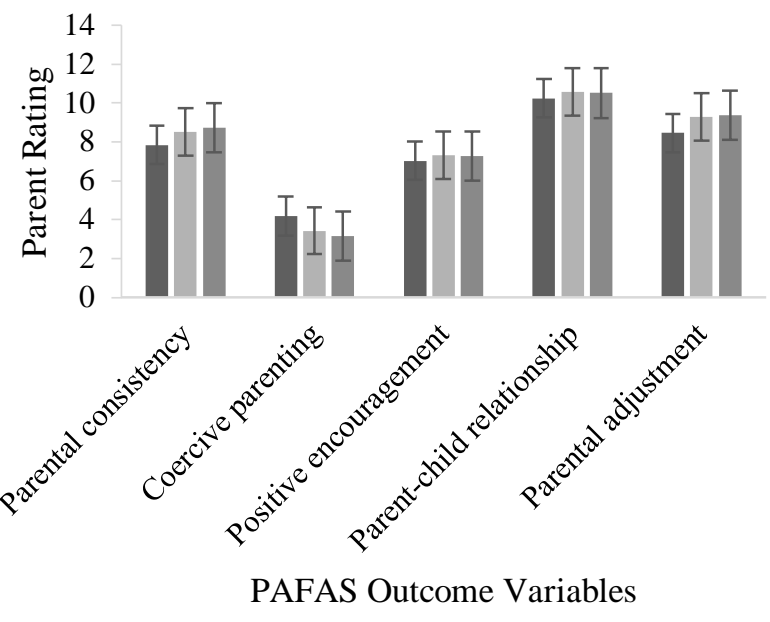

- Pre-Intervention $\square$ Post-Intervention $\quad$ Follow-up

Figure 2. Mean rating of parental consistency, coercive parenting, positive encouragement, parent-child relationship and parental adjustment across intervention time. Error bars indicate standard error. Note. All subscales in the figure are positively scored for ease of interpretation, where higher scores indicate higher levels of the outcome.

The main effect of time on child problem behaviour was significant, $F(1.90,405.80)=10.42, p<.001$. Follow-up pairwise contrasts revealed a significant reduction in child problem behaviour from pre- to post-intervention, $F(1,214)=9.79, p=.002$, and from pre-intervention to follow-up, $F(1,214)=$ $16.55, p<.001$ (see Figure 3). Therefore, schoolbased SSTP improved children's behaviour.

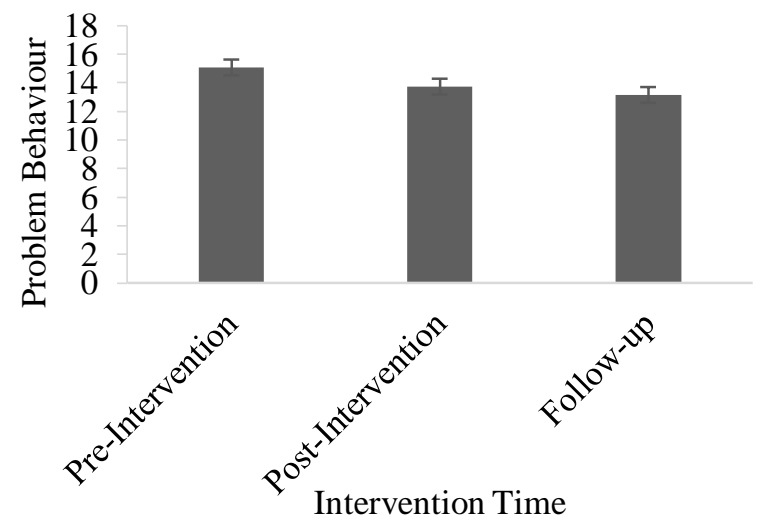

Figure 3. Mean parent rating for child problem behaviour at each time-point. Error bars indicate standard error.

The ANOVA examining parental self-efficacy revealed a significant main effect of time, $F(2,428)$ $=42.81, p<.001$. Follow-up comparisons revealed a significant increase in parents' self-efficacy from pre- to post-intervention, $F(1,214)=58.47, p<$ .001 , and from pre-intervention to follow-up, $F(1$, 
$214)=60.39, p<.001$ (see Figure 4$)$. This suggests that parents felt more competent in their parenting after receiving school-based SSTP.

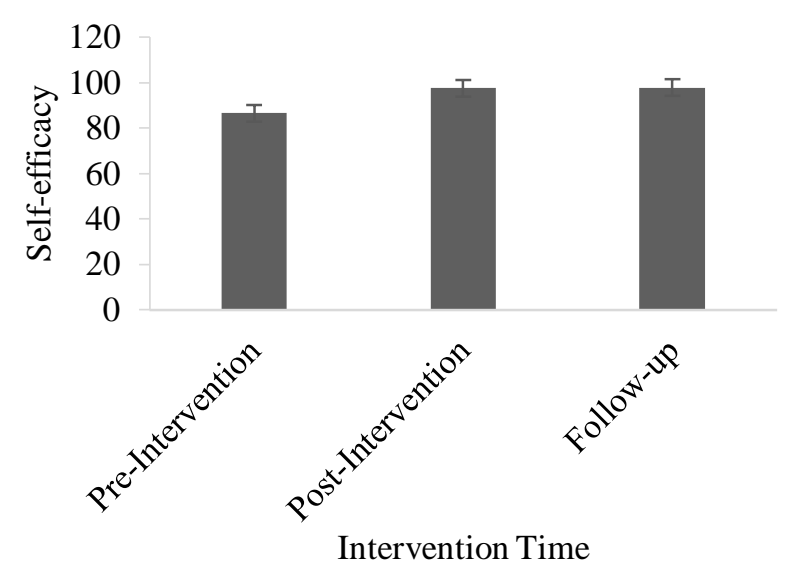

Figure 4. Mean rating of self-efficacy at each timepoint. Error bars indicate standard error.

As displayed in Table 3, the effect sizes given by Glass' $\Delta$ were nearing medium for all outcome variables. Parenting practices and parenting efficacy appeared to have made the greatest gains from the intervention.

Table 3. Effect size (Glass' $\Delta$ ) for each outcome variable from pre- to post-intervention and from preintervention to 12-month follow-up.

\begin{tabular}{lcc}
\hline Outcome Variable & Pre-Post & $\begin{array}{c}\text { Pre-Follow- } \\
\text { up }\end{array}$ \\
\hline Parenting practices & 0.44 & 0.53 \\
Parental adjustment & 0.33 & 0.32 \\
Problem behaviour & 0.21 & 0.29 \\
Parental self-efficacy & 0.53 & 0.53 \\
\hline
\end{tabular}

Quantitative responses from the Client Satisfaction Questionnaire (CSQ) indicated that parents were satisfied with the SSTP intervention, with an overall mean rating of 5.16 (on a 7-point scale). The highest mean rating was for the quality of the service received, where most participants $(87.3 \%)$ indicated that the service quality was good or excellent. The lowest mean rating was for the improvement in relationship with the partner, with almost half the participants (49.3\%) indicating that they saw low to moderate improvements in the relationship with their partner. The qualitative responses from parents were represented in four main themes: increased confidence and skill for parents (11.6\%), improved behaviour and skill of children (8.7\%), positive experience with the facilitator (15.9\%), and the need for ongoing support with strategies $(7.3 \%)$. Parents continued to seek support from education staff $(35.7 \%)$ and other health professionals (53.3\%). One parent remarked, "The program would be more effective if the facilitator could see the child in action because it is difficult to explain the exact situation you're facing...facilitators should work in conjunction with the parents and staff at [the school], enabling the three parties to work together and share ideas." These qualitative findings provide some preliminary support for school-based SSTP in creating an overlap between two important stakeholders in the child's life: the parent and the teacher.

\section{Discussion \& Conclusion}

Discussion. This study investigated the previously established benefits of Stepping Stones Triple P (SSTP) in a novel context. Specifically, we explored the effects of school-based delivery of SSTP by education professionals, on the parent and child outcomes. Consistent with our hypotheses and previous literature demonstrating the benefits of SSTP (Hodgetts et al., 2013; Roberts et al., 2006; Roux et al., 2013; Sofronoff et al., 2011; Tellegen \& Sanders, 2013; Whittingham et al., 2009), we found an improvement in child behaviour, parenting practices, and parental adjustment post-intervention. Parental self-efficacy increased immediately after the intervention, which is consistent with the findings of Hodgetts et al. (2013) but inconsistent with those of Sofronoff et al. (2011) and Whittingham et al. (2009) who found a delayed effect. Contrary to our hypothesis, the effect of the intervention on parent and child outcomes was not dependent on the level of intervention that parents received.

Upon closer observation of parenting practices, we found a marked reduction in coercive parenting, an improvement in parenting consistency, the relationship between parents and their child, and the use of positive encouragement. This distinction in aspects of parenting enables practitioners to tailor the intervention to each parent based on their individual needs. As expected, the improvements were maintained at a 12-month follow-up. Overall, parents reported moderate to high satisfaction with the program.

To date, studies have not explored the effects of SSTP when delivered in special education settings and by education professionals. These novel findings provide an evidence-based framework for the effectiveness of school-based SSTP in supporting parents to effectively manage their child's disability and enhance their developmental outcomes. Equipping parents with positive 
parenting strategies is crucial to improving the child's behaviour and learning ability, both at home and at school (Sanders et al., 2017). This can also result in flow-on effect of increased attention and learning for all children in the classroom. Furthermore, school-based SSTP can be beneficial for special education teachers who experience significant stress due to behavioural problems of children (Clunies-Ross et al., 2008).

The qualitative findings of program satisfaction provide preliminary evidence for the potential additional benefit of school-based SSTP on homeschool partnership (HSP). Several parents reported an ongoing support from the facilitators (i.e. education professionals), with a noteworthy comment on the importance of the facilitator being able to directly witness the child's behaviour. Ongoing support from the education staff may occur due to the pre-existing relationship and continuing contact that parents have with the school. The facilitator's familiarity with the child combined with the novel information provided by parents during the intervention would allow facilitators to accurately aid parents in promoting the well-being of children and fostering consistency in practice for them. Further investigating this finding is crucial so as to identify if school-based SSTP can aid in overcoming barriers to effective HSP, such as lack of communication and understanding between parents and teachers.

These results also showcase that low-intensity interventions, such as seminars, are equally effective in improving child and parent outcomes as high-intensity interventions, such as group and individual sessions. This is significant because parenting programs have a limited reach, with common barriers being noted as time constraints, work demands, cost, and child care issues (Murray, Woodruff, Moon, \& Finney, 2015). Providing brief parenting interventions like seminars would be ideal for attracting parents that face such barriers (Barrett, 2010). Some of the barriers could be alleviated by delivering school-based parenting intervention as the intervention can be scheduled around school drop-off and pick-up times, or when children are in before- or after-school care (Sanders et al., 2017).

Although randomised controlled trials (RCTs) are considered to be the most rigorous studies, numerous RCTs, including a meta-analysis (Tellegen \& Sanders, 2013), have previously established the efficacy of SSTP. The goal of the present study, therefore, was to adopt a public health approach to the delivery of parenting interventions and conduct an effectiveness trial of school-based SSTP. This is because parents have regular contact with the school, thereby making it a natural home for parenting interventions and substantially increasing its reach. The findings of this study support the generalisability of SSTP effects when facilitators are education professionals who would have varying levels of experience in psychological and parenting interventions. Nevertheless, the limitation of this study was that all outcomes were measured via subjective, self-report scales. Although items were both positively and negatively formulated, there exists the possibility of inaccurate responses as a result of faking or a lack of self-insight of participants. Furthermore, conclusions made regarding the effect of schoolbased SSTP on HSP are merely circumstantial at this stage as this study did not directly examine this effect.

Conclusions. Ultimately, this study demonstrates the effectiveness of school-based SSTP in empowering parents and improving the learning and development of children with a disability. The qualitative responses from parents provide nascent evidence for the potential of school-based SSTP to influence HSP in special education. Given the importance of overlap and consistency between home and school for children with a disability, an extension to this study will be highly beneficial to specifically explore the potential of school-based SSTP to enhance the partnership between homes and schools in special education.

\section{Acknowledgement}

I would like to acknowledge my supervisors Dr. Julie Hodges and Dr. Jamin Day for their guidance and support through every stage in this project. I would also like to thank all researchers involved in the Stepping Stones Triple P Project for sharing the data to make this research possible.

\section{References}

Alimovic, S. (2013). Emotional and behavioural problems in children with visual impairment, intellectual and multiple disabilities. Journal of Intellectual Disability Research, 57(2), 153-160. doi:10.1111/j.1365-2788.2012.01562.x

Avvisati, F., Gurgand, M., Guyon, N., \& Maurin, E. (2014). Getting parents involved a field experiment in deprived schools. The review of economic studies, 81(1), 57-83. doi:10.1093/restud/rdt027

Bano, H., Anjum, N., Rahman, F., Sadia, T., \& Sarwar, N. (2013). Home-school partnership: A perspective of stakeholders in special education. Interdisciplinary 
Journal of Contemporary Research In Business, 5(7), 96104. Retrieved from http://www.ijcrb.webs.com/

Barrett, K. (2010). Stepping Stones-Triple P: A study of the acceptability and usefulness of a parenting seminar series for parents of a child with a developmental disorder (Unpublished honours dissertation). The University of Queensland, Australia.

Bronfenbrenner, U. (1977). Toward an experimental ecology of human development. American Psychologist, 32(7), 513531. doi:10.1037/0003-066X.32.7.513

Clunies-Ross, P., Little, E., \& Kienhuis, M. (2008). Selfreported and actual use of proactive and reactive classroom management strategies and their relationship with teacher stress and student behaviour. Educational Psychology, 28(6), doi:10.1080/01443410802206700

693-710.

Eddy, J. M., Leve, L. D., \& Fagot, B. I. (2001). Coercive family processes: A replication and extension of Patterson's coercion model. Aggressive Behavior, 27(1), 14-25. doi:10.1002/1098-2337(20010101/31)27:1<14::AID$\mathrm{AB} 2>3.0 . \mathrm{CO} 2-2$

Emser, T. S., Mazzucchelli, T. G., Christiansen, H., \& Sanders, M. R. (2016). Child Adjustment and Parent Efficacy Scale-Developmental Disability (CAPES-DD): First psychometric evaluation of a new child and parenting assessment tool for children with a developmental disability. Research in Developmental Disabilities, 53-54, 158-177. doi:10.1016/j.ridd.2015.09.006

Epstein, J. L. (2010). School/family/community partnerships: Caring for the children we share. Phi Delta Kappan Magazine, 92(3), 81-96. doi:10.1177/003172171009200326

Glueck, C. L., \& Reschly, A. L. (2014). Examining congruence within school-family partnerships: Definition, importance, and current measurement approaches. Psychology in the Schools, 51(3), 296-315. doi:10.1002/pits.21745

Hodgetts, S., Savage, A., \& McConnell, D. (2013). Experience and outcomes of stepping stones triple $\mathrm{P}$ for families of children with autism. Research in Developmental Disabilities, $\quad 34(9), \quad 2572-2585$. doi:10.1016/j.ridd.2013.05.005

Jack, G. (2000). Ecological influences on parenting and child development. The British Journal of Social Work, 30, 703-720. doi:10.1093/bjsw/30.6.703

Mazzucchelli, T. G., Kane, R. T., Hodges, J., Sofronoff, K., Sanders, M. R., Schoch, M., . . . Tellegen, C. (2017). Parenting and Family Adjustment Scales (PAFAS): Validation of a brief parent-report measure for use with families who have a child with a developmental disability Manuscript in preparation.

Moes, D. R., \& Frea, W. D. (2000). Using family context to inform intervention planning for the treatment of a child with autism. Journal of Positive Behavior Interventions, 2(1), 40-46. doi:10.1177/109830070000200106

Murray, K. W., Woodruff, K., Moon, C., \& Finney, C. (2015). Using text messaging to improve attendance and completion in a parent training program. Journal of Child and Family Studies, 24(10), 3107-3116. doi:10.1007/s10826-015-0115-9

Patrikakou, E. N., Weissberg, R. P., Redding, S., \& Walberg, H. J. (2005). School-family partnerships for children's success (Vol. 48). New York: Teachers College Press.
Roberts, C., Mazzucchelli, T., Studman, L., \& Sanders, M. R. (2006). Behavioral family intervention for children with developmental disabilities and behavioral problems. Journal of Clinical Child \& Adolescent Psychology, 35(2), 180-193. doi:10.1207/s15374424jccp3502_2

Roux, G., Sofronoff, K., \& Sanders, M. (2013). A randomized controlled trial of group Stepping Stones Triple P: A mixed-disability trial. Family Process, 52(3), 411-424. doi:10.1111/famp.12016

Sanders, M. R., Healy, K. L., Grice, C., \& Del Vecchio, T. (2017). Evidence-based parenting programs: Integrating science into school-based practice. In M. Thielking \& M. D. Terjesen (Eds.), Handbook of Australian School Psychology: Integrating International Research, Practice, and Policy (pp. 537-551). Cham, Switzerland: Springer International Publishing.

Sanders, M. R., Mazzucchelli, T. G., \& Studman, L. J. (2004) Stepping Stones Triple P: The theoretical basis and development of an evidence-based positive parenting program for families with a child who has a disability. Journal of Intellectual and Developmental Disability, 29(3), 265-283. doi:10.1080/13668250412331285127

Sheldon, S. B., \& Epstein, J. L. (2002). Improving student behavior and school discipline with family and community involvement. Education and Urban Society, 35(1), 4-26. doi:10.1177/001312402237212

Sheridan, S. M., \& Moorman, K. E. (2015). Foundational Aspects of Family-School Partnership Research: Cham: Springer International Publishing: Imprint: Springer.

Sofronoff, K., Jahnel, D., \& Sanders, M. (2011). Stepping Stones Triple $\mathrm{P}$ seminars for parents of a child with a disability: A randomized controlled trial. Research in Developmental Disabilities: A Multidisciplinary Journal, 32(6), 2253-2262. doi:10.1016/j.ridd.2011.07.046

Sterian, M., \& Mocanu, M. (2013). Family-school partnerships: Information and approaches for educators. Euromentor Journal, 4(2), 166-174. Retrieved from http://euromentor.ucdc.ro/en/

Suter, S. (2006). Meaningful differences in the everyday experience of young American children. European Journal of Pediatrics, 165(4), 282-282. doi:10.1007/s00431-005-0010-2

Tellegen, C. L., \& Sanders, M. R. (2013). Stepping Stones Triple P-Positive Parenting Program for children with disability: A systematic review and meta-analysis. Research in Developmental Disabilities: A Multidisciplinary Journal, 34(5), 1556-1571. doi:10.1016/j.ridd.2013.01.022

Turner, K. M. T., Sanders, M. R., \& Markie-Dadds, C. (2002). Facilitator's manual for group Triple $P$ Milton, Queensland: Triple P International.

Whittingham, K., Sofronoff, K., Sheffield, J., \& Sanders, M. (2009). Stepping Stones Triple P: An RCT of a parenting program with parents of a child diagnosed with an autism spectrum disorder. Journal of Abnormal Child Psychology, 37(4), 469-480. doi:10.1007/s10802-0089285-x

Wilder, S. (2014). Effects of parental involvement on academic achievement: A meta-synthesis. Educational Review, 66(3), 377-397. doi:10.1080/00131911.2013.780009 